\title{
A Case of Pediatric Intoxication Due to Overdose Cylopentolate Ophthalmic Solution Application
}

\author{
Canan Ünlü, Betül Şen, Sibel Devrim, İbrahim Öztürk, Esin Öner, Yağmur Üstün, Melek Güra Çelik \\ Clinic of Anesthesiology and Reanimation, Medeniyet University Göztepe Training and Research Hospital, İstanbul, Turkey \\ Cite this article as: Ünlü C, Şen B, Devrim S, Öztürk i, Öner E, Üstün Y, et al. A Case of Pediatric Intoxication Due to Overdose Cylopentolate \\ Ophthalmic Solution Application. JAREM 2017; 7: 92-4.
}

\begin{abstract}
Cyclopentolate is a frequently used topical mydriatic and cycloplegic drug by ophthalmologists for diagnosing and preoperatively evaluating the patients. We aimed to report a case of delirium due to high dose cyclopentolate application for an ophthalmologic examination. Cyclopentolate drops were used in a 6 years old male patient without any co-existing disease for an examination at the ophthalmology polyclinic. However, it was applied 3-three times as 3 drops with 15 minutes intervals on his two eyes by his mother. After the application he experienced nonsensical speech, mydriasis, and mouth dryness appeared and he was evaluated as having anticholinergic syndrome in the emergency department. For this reason, he was admitted to the intensive care unit, and dilated pupils and a negative pupillary light reflex were detected. Systemic physical examination resulte were evaluated as normal. There was an increase in the speech rate and motor activity, and distractibility and visual hallucinations were present. He was oxygenated by using a face mask. An improvement was seen at his speech and behavioral functions after 3 hours. And he was discharged after 5 hours with remission. We aimed to emphasize that cyclopentolate might be applied carefully by health care providers tofor the prevention of intoxication because of the serious systemic adverse effects which can cause intoxication.
\end{abstract}

Keywords: Cyclopentolate, intoxication, delirium, overdose

\section{INTRODUCTION}

Cyclopentolate hydrochloride ophthalmic solution is a drug frequently used by ophthalmologists before an ophthalmologic examination. An eye drop having a cycloplegic and mydriatic action is required for the fundus examination before the refraction test and for inflammatory diseases of the eye (1). The mydriatic and cycloplegic actions of cyclopentolate, which is generally preferred due to these effects and used locally, occur in 30-60 min following its application and can last up to $24 \mathrm{~h}$ (2). A form of cyclopentolate with lower concentration came into use because of its systemic adverse effects (3). This drug inhibits the response to the cholinergic innervation of the iris sphincter muscle and causes pupil dilation. It also leads to cycloplegia by preventing cholinergic stimulation of the ciliary muscle that provides accommodation (4). Its effect starts and ends faster than those of atropine or scopolamine (4).

In Turkey, this drug is sold with the tradename of cyclopentalote hydrochloride 1\% ophthalmic solution (5). Cyclopentolate can cause systemic side effects, particularly in pediatric patients when solutions with concentration of $>0.5 \%$ are used (5). Here, we report the development of intoxication after the application of cyclopentolate eye drop in a pediatric patient.

\section{CASE REPORT}

A 6-year-old male patient without any co-existing systemic disease was admitted to the outpatient clinic of ophthalmology for an ophthalmic examination. His mother was told that his examination would be performed after applying cyclopentolate eye drop (Sikloplejin Eye Drops 1\%, Abdi ibrahim, istanbul, Turkey) and was instructed regarding the application of the drug. However, she misunderstood the instructions regarding the application, and she applied the solution three times with three drops, instead of one drop, at one application at 15-min intervals in both eyes. Following the application of the drug, the patient was taken into the emergency unit because of the development of incoherent speech, mouth dryness, and mydriasis. After his vital signs were monitored, he was diagnosed with anticholinergic syndrome, and he was admitted to the intensive care unit for close monitoring after obtaining consent from his parents.

During his initial examination in the intensive care unit, dilated pupils and negative light reflex were detected. No 
additional neurological finding was observed. In systemic physical examination, respiratory, cardiovascular, and gastrointestinal findings and vital signs were normal. Incoherent and increased speech rate and motor activity, distractibility, and visual hallucinations were observed. However, no auditory, olfactive, or tactile hallucination was observed. Thought content of the patient, who had affective disorder, was normal. His thought flow was increased and with loose associations.

The patient did not display agitation. Results of his laboratory analyses were normal. He was oxygenated using a face mask. His speech and behavioral functions returned to normal after $3 \mathrm{~h}$. Remission was observed approximately after $5 \mathrm{~h}$ without any treatment. Considering his normal physical examination and psychological findings, he was discharged after $24 \mathrm{~h}$.

\section{DISCUSSION}

Topical drug-induced systemic toxicity was observed in a 6-year-old male patient with no underlying disease, who was admitted to the outpatient ophthalmology clinic for squinting and was mistakenly given an overdose of cyclopentolate hydrochloride by his mother (three times as three drops, instead of one drop, at one time). Except mydriasis, incoherent speech, increased motor activity, and distractibility, no other neurological finding was detected in the patient.

Cyclopentolate has two types of adverse effects: ocular (increased intraocular pressure, lacrimal duct blockade, corneal damage, and cloudy vision) and systemic (hypertension, tachycardia, arrhythmia, shivering, hallucination, confusion, agitation, aggressive behaviors, disorientation, and incoherent speech and behaviors) (5). Although acute toxic psychosis is rarely seen in pediatric cases, the incidence of behavioral disorders is not exactly known (6).

It is difficult to say that the incidence of systemic adverse effects of cyclopentolate is associated with only the dose of the drug (7). However, the risk for the development of side effects increases at higher concentrations and doses of cyclopentolate. In a study that was conducted in old times when $2 \%$ solutions of cyclopentolate were used, systemic adverse effects were observed in $10(15.1 \%)$ of 66 adult patients. Therefore, the use of $2 \%$ solution was restricted. A recent prospective randomized controlled study reported that $1 \%$ cyclopentolate solution was adequate in patients aged 3.520 years, and the frequency of side effects was lower (8). On the other hand, in a case wherein acute psychotic reaction developed despite the application of $1 \%$ solution, researchers performed a chemical analysis and found that the concentration of cyclopentolate that was given was $1.31 \%$, not $1 \%$ (9). Systemic adverse effects may also develop in patients having no co-existing disease and who are given appropriate concentration or dose of the drug $(1,5)$.
Cyclopentolate-induced adverse effects can lead to hypersensitivity reactions and acute respiratory distress as well as ocular and parasympathetic effects $(10,11)$. Although topical drug administration is classified as a form of local drug application, it should be remembered that eye drops can join the systemic circulation through the conjunctiva (12). Furthermore, it should be kept in mind that absorption of topical drugs can reach a level as high as that in systemic administration. Therefore, utmost attention should be paid to avoid overdose.

\section{CONCLUSION}

It should be kept in mind that although rare, systemic adverse effects of cyclopentolate can develop, particularly at concentrations of $>0.5 \%$. Therefore, this drug should be administered when emergency medical intervention is required, especially for pediatric cases. Moreover, the drug should be given by a health care provider to prevent possible malpractice.

Informed Consent: Written informed consent was obtained from patients' parents who participated in this study.

Peer-review: Externally peer-reviewed.

Author Contributions: Concept - C.Ü., B.Ş., S.D., I.Ö.; Design - I.Ö., E.Ö., Y.Ü.; Supervision - M.G.Ç., S.D.; Resources - C.Ü., B.Ş., S.D., I.Ö., E.Ö., Y.Ü., M.G.Ç.; Materials - E.Ö., Y.Ü.; Data Collection and/ or Processing - C.Ü., B.Ş., I.Ö.; Analysis and/or Interpretation - B.Ş., i.Ö., S.D.; Literature Search - I.Ö., S.D.; Writing Manuscript - i.Ö., C.Ü.; Critical Review - M.G.Ç.

Conflict of Interest: No conflict of interest was declared by the authors.

Financial Disclosure: The authors declared that this study has received no financial support.

\section{REFERENCES}

1. Kara S, Gencer B, Ekim YÖ, Arıkan S. Bir Yetişkinde Siklopentolat Damla Kullanımı Sonrası Gelişen Akut Deliryum. Int J Clin Res 2013; 1: 76-8.

2. Lovasik JV. Pharmacokinetics of topically applied cyclopentolate $\mathrm{HCl}$ and tropicamide. Am J Optom Physiol Opt 1986; 63: 787-803. [CrossRef]

3. Awan KJ. Adverse systemic reactions of topical cyclopentolate hydrochloride. Ann Ophthalmol 1976; 8: 695-8.

4. Gordon DM, Ehrenberg MH. Cyclopentolate hydrochloride: a new mydriatic and cycloplegic agent: a pharmacologic and clinical evaluation. Am J Ophthalmol 1954; 38: 831-8. [CrossRef]

5. Ağın H, Gerçek H, Kutlu A, Gülez N, Atlıhan F. Topikal siklopentolat kullanımına bağlı gelişen deliryum tablosu: Bir vaka takdimi. Çocuk Sağlığı ve Hastalıkları Dergisi 2008; 51: 39-42.

6. Sikloplejin ürün monografı. Available from: http://www.abdiibrahim. com.tr/product-files/file/20130419-sikloplejin-damla-kubpdf_24589/ view.aspx. (07.12.2015'te ulaşılmıştır).

7. Awan KJ. Adverse systemic reactions of topical cyclopentolate hydrochloride. Ann Ophthalmol 1976; 8: 695-8.

8. Bagheri A, Givrad S, Yazdani S, Reza Mohebbi M. Optimal dosage of cyclopentolate $1 \%$ for complete cycloplegia: a randomized clinical trial. Eur J Ophthalmol 2007; 17: 294-300. 
9. Huismans $\mathrm{H}$. Intoxikationspsychose nach Cyclopentolat-HCl (Zyklolat). Klin Monatsbl Augenheilkd 1979; 175: 100-2.

10. Jones LW, Hodes DT. Possible allergic reactions to cyclopentolate hydrochloride: case reports with literature review of uses and adverse reactions. Ophthalmic Physiol Opt 1991; 11: 16-21. [CrossRef]
11. Derinoz O, Emeksiz HC. Use of physostigmine for cyclopentolate overdose in an infant. Pediatrics 2012; 130: e703-5. [CrossRef]

12. Pooniya V, Pandey N. Systemic toxicity of topical cyclopentolate eyedrops in a child. Eye (Lond) 2012; 26: 1391-2. [CrossRef] 